\title{
Turismo em Unidades de Conservação: Parques Estaduais de Campos do Jordão
}

\author{
Alexandre Schiavetti ${ }^{1}$ \\ Celina Foresti ${ }^{2}$
}

RESUMO: Apresenta alguns princípios, importância, impactos e situação das unidades de conservação, em relação à prática do ecoturismo. Como estudo de caso é apresentada realidade de sua prática em parques estaduais de Campos do Jordão, São Paulo, Brasil.

PALAVRAS-CHAVE: ecoturismo, unidades de conservação, parque estadual, manejo, Campos do Jordão, São Paulo, Brasil.

ABSTRACT: This work has as objective to present some beginnings, importance, impacts and situation of the conservation units, with relationship the tourism practice. With study case it is discuss the tourism in the State Parks of Campos do Jordão, São Paulo, Brazil.

KEYWORDS: ecotourism, conservation units, statepark, management, Campos do Jordão, São Paulo, Brazil.

\section{Introdução}

Os dados da Organização Mundial do Turismo indicam que, no plano internacional, o turismo é a atividade econômica mais importante e promissora depois da indústria petrolífera e da indústria bélica. As transações turísticas foram responsáveis por 6,8\% do comércio mundial de bens e serviços em 1989 (Serson, 1992).

O setor de turismo contribui substancialmente para as transformações econômicas e sociais de certas regiões, mas é inegável que esta contribuição poderia ser

1. Bacharel em Ecologia pela Universidade do Estado de Sảo Paulo. Mestre em Ciências da Engenharia Ambiental pela Universidade de Sảo Paulo. Doutorando em Ecologia e Recursos Naturais pela Universidade Federal de Sảo Carlos. Professor no Departamento de Ciências Agrárias e Ambientais da UESC, Ilhéus, Bahia. End.: Rodovia Ilhéus - Itabuna, kml6 - 45650-000 - Ilhéus - BA. E-mail: aleschi@ hotmail.com

2. Professora Doutora no Departamento de Ecologia da Universidade do Estado de Sảo Paulo. Orientadora no Programa de Pós-Graduação em Ciências da Engenharia Ambiental do CRHEA da Universidade de São Paulo. 
ampliada, principalmente se a opção do turismo ecológico fosse explorada mais intensamente (Comune, 1991). A demanda crescente dos turistas por viagens que proporcionem o contato direto com a natureza, coloca todas as regiões do Brasil em posição privilegiada como destinadas para a demanda do turismo ecológico e do aventura (Ferrão et al., 1992)

O Instituto Brasileirode Turismo(Embratur), órgãooficial da atividade no país, elaborou uma legislação específica para o desenvolvimento do turismo ecológico e conceitua-o como:

atividades desenvolvidas em localidades com potencial ecológico, de forma conservacionista, procurando conciliar a exploraçāo turistica com o meio ambiente, harmonizando as açōes com a natureza e oferecendo aos turistas um contato intimo com os recursos naturais e culturais da regiāo, buscando a formaçāo de uma consciência ecológica nacional (Embratur, 1991)

As regiões da Amazônia e do Pantanal se destacam neste contexto pelo seu tamanho, e nas quais o turismoecológico épraticadomais intensamente (Ruschmann, 1992). Esse tipo de turismo, denominado geralmente de ecoturismo, se diferencia das atividades comuns de lazer, não podendo prescindir de respaldo técnico-científico para sua estruturação enquanto atividade ecológica (Ortega et al., 1992), gerando receitas para as regiões nas quais é desenvolvido e promovendo a integração das comunidades locais na distribuição de renda.

No ecoturismo, segundo Pagani et al. (1996), vários pontos devem ser considerados:

- evitar as grandes concentrações humanas;

- integrar o turismo ao meio ambiente mediante arquitetura adaptdada.

- preservar e valorizar o patrimônio natural, histórico e cultural;

- envolver a participação das comunidades locais;

- proporcionar a aquisição de consciência pelas populações locais e pelos turistas a respeito da necessidade de proteger as riquezas naturais e do patrimônio.

Segundo Boo (1990), o ecoturismo fundamenta-se em doisprincípios básicos: o primeiro refere-se à proteção dos recursos naturais das áreas visitadas que não poderá ser comprometida, e o segundo diz respeito às populações vizinhas a essas áreas que devem ser envolvidas e beneficiadas pelo ecoturismo.

\section{Relaçāo Turismo e Unidades de Conservaçāo}

As unidades de conservação, tanto de uso indireto como direto, deveriam elaborar seus planos de manejo considerando o zoneamento e os programas de manejo para áreas de interesse turístico. As categorias que contemplam o desenvolvimentod

básicos do manejo, são os parques, os monumentos naturais, as reservas de fauna as áreas de proteção ambiental (APA) e as florestas nacionais.

As áreas especiais de interesses turísticos, previstas pela Embratur, destinamse justamente a priorizar o desenvolvimento do turismo em áreas com reconhecida vocação natural para essa atividade, podendo compartilhá-la de forma equilibrada com outras formas de ocupação do território (Pires, 1993). Uma das poucas áreas implantadas com esta forma de manejo é a área especial de interesse turístico do Marumbi(PR).

Nas Unidades de Conservação (UC), têm-se trabalhado o ecoturismo numa aproximação muito forte com a educação ambiental (Furlan, 1996) ou com a interpretação ambiental (Pagani et al., 1996), das quais muitas estratégias têm sido adaptadas para os programas de ecoturismo.

O turismo, como alternativaeconômica para a região em que está inserida uma UC, pode possibilitar a sua entrada no desenvolvimento regional, visto que essas áreas exercem forte atração no público em geral (Schiavettiet al., 1997). Porém devese considerar a forte dependência da comunidade vizinha pela atividade turística, em virtude da sazonalidade que esta atividade possui.

Nessas áreas há forte variação temporal na sua visitação, o que implica grandes concentrações humanas em determinadas épocas. Osemeobo (1989) identificou os problemas de áreas verdes urbanas e zoológicos da Nigéria, mostrando que a sazonalidade do público, principalmente em épocas de férias, implica grandes impactos para as áreas estudadas. No Brasil, Magri et al. (1990), trabalhando em um Parque Estadual paulista, mostraram que a variação d a visitação deve-se à freqüência de público nas áreas vizinhas, no caso uma estância balneária que tem elevado o número de visitantes na temporada de verão.

Em virtude das grandes concentrações em épocas determinadas, a tendência nessas áreas é a abertura de novos locais para a recreação, propiciando diferentes experiências recreativas, visando a espacialização dos visitantes (Morris \& Dickinson, 1987; Nelson, 1994). Porém, após alguns anos, há estagnação natural do número de visitantes, o que pode gerar a estagnação também na economia local.

O aumento do número de turistas ou a implantação de planos de desenvolvimento turístico não deve ser uma estratégia para todas as UC; somente certas áreas têm infra-estrutura, facilidades de transporte e hotéis para suportar esta indústria. Em primeiroplano, benefícios do turismo podem ser evidentes em nível nacional, embora padrões culturais e econômicos locais possam ser seriamente modificados (Budowsky, 1977).

O turismo e a recreação, atividades propostas como parte dos objetivos diretos de algumas categorias de UC, são atividades causadoras de fortes mudanças ambientais e socioculturais, tanto local como regional. Budowski (1976) sugeriu três diferentes relações entre áreas que têm objetivos primários de conservação e turísticos: 
- o conflito, em que o turismo é destrutivo à natureza;

- a coexistência, em que há pouco contato;

- a simbiose, em que os interesses de ambos beneficiam a relação.

Vários estudos demonstram o impacto causado pelo turismo em áreas naturais, bem como colocam em prova sua exploração econômica, conforme sintetizado a seguir.

Os trabalhos realizados com oimpacto do turismoem aves das Ilhas Galápagos (Equador), demonstram que estas alteram seu comportamento e reprodução quando em contato íntimo com o turista (Burger \& Gochfeld, 1993; Burger et al., 1995). Este tipo de impacto também é sentido nos cetáceos, como descrito por Blane \& Jaakson (1994), nas belugas (Delphinapterus leucas) do rio São Lourenço e nas orcas (Orcinus orca), no litoral do Canadá, por Duffus \& Dearden (1993).

Os impactos observados na flora, demonstrado por Sinha (1992), nas ilhas Andaman e Nicobar(Índia), mostrama reduçãopopulacionaldas espécies endêmicas locais. Estes mesmosimpactosforam determinados em uma barreira de recifes de coral no mar Vermelho (Egito) por Hawkins \& Roberts (1994), e na grande barreira de recifes da Austrália, onde algumas espécies estão mostrando taxas muito baixas de restabelecimento após o pisoteio (Liddle \& Kay, 1987).

Jusoff (1989) tentou determinar, em uma Floresta Nacional da Malásia, o impacto da recreação no solo, o qual, pelo seu trabalho, não se altera com o uso. Porém, Cole \& Marion (1988) avaliaram o impacto areal da visitação em áreas de "camping" e trilhas, nos Estados Unidos, e determinaram que o impacto é diretamente proporcional à quantidade de uso.

Pesquisas relatadas por Cole apud Tulik (1992), referentes aos Estados Unidos, mostram perturbações ambientais provocadas pelos efeitos de caminhadas ou por veículos em áreas de acampamentos, em trilhas e onde foram praticadas outras atividades recreacionais.

O turismo em áreas marinhas pode causar, segundoTommasi (1992), diversos impactos sobre as variáveis ambientais, tais como: diminuição da penetração da luz na água, em virtude da elevação do material particulado em suspensão, microorganismos de origem fecal, assoreamento, etc.

No Brasil, os impactos ambientais do turismo ecológico não têm sido estudados de forma sistemática, porém pode-se considerar que os impactos negativos superam os positivos (Ruschmann, 1993). Conforme Mariani \& Gonçalves (1996), o Pantanal Sul Mato-Grossense está sofrendo diversos impactos pela atividade turística, como o derramamento de óleo por barcos à motor.

A análise das consequiências da interação do turismo e UC não é só de impactos adversos e custos. Trabalhos como o realizado por Aulicino (1994), através de métodos quantitativos, demonstram que o turismo pode gerar qualidade de vida, melhorando as condições das comunidades vizinhas.

$\mathrm{O}$ crescimento do interesse turístico em algumas áreas também produz benefícios ambientais. Como benefícios, tem-se a forma predominante de aumento do suporte financeiro para a preservação da área e adequação do manejo, como um resultado do aumento da consciênciae sensibilização trazida pelo turismo (Stankey, 1989). Esta sensibilização e aumento da consciência podem ser realizados através de programas de educação ambiental (Pádua, 1994).

A utilização de metodologias de planejamento para as áreas naturais, objetivando a minimização dos impactos da recreação, é a mais efetiva forma de se evitar danos biológicos e/ou físicos a estas áreas. Através da espacialização de informações, tais como facilidades de acesso e situação geográfica, pode-se dividir as áreas em locais propícios ou não para a recreação.

A utilização de sistemas de informações geográficas é uma das ferramentas indicadas para esta forma de planejamento, sendo ainda usados na determinação de impactos ambientais (Bubel, 1995), na verificação de informações biológicas (Scott et al., 1987) e até na prevenção de incêndios (Cortes, 1993). Davis et al. (1990) delinearam quatro aplicações básicas para um sistema de informação geográfica dentre eles a alocação de áreas-chaves para a criação de Unidades de Conservação, através da utilização de análise de falhas dos hábitats protegidos.

O planejamento de parques e reservas inclui diversas variáveis, tanto físicas como biológicas, sendo ambas distribuídas heterogeneamente no espaço. Através da utilização de sistemas de informações geográficas (SGI), pode-se definir padrões e oferecer soluções para o gerenciamento destas Unidades. Schiavetti (1997) utilizando um SIG, propôs um zoneamento recreativo para o Parque Estadual dos Mananciais de Campos do Jordão (SP), no qual três classes de restrições puderam serseparadas, visando a utilização desta área, tanto para a recreação ao ar livre como para a conservação de espécies.

\section{Estudo de Caso: Parques Estaduais de Campos do Jordão}

O município de Campos do Jordão localiza-se na zona leste do Estado de São Paulo, tendo a posição geográfica determinada pelas coordenadas de $22^{\circ} 44^{\prime} S$ e 4530'W. Suaárea é de $269 \mathrm{~km}^{2}$, limitando-se com Pindamonhangaba, pelas cristas da Serra da Mantiqueira a uma altitude média de $1.900 \mathrm{~m}$, e com o Estado de Minas Gerais, em altitudes que vão decrescendo progressivamente até $1.000 \mathrm{~m}$.

O clima de Campos do Jordão foi considerado por Setzer (1966), como mesotérmico,com verõesbrandose sem estação seca. Pela classificaçãode Köeppen, oclimaé "Cfb", que significa clima subtropical de altitude, mesotérmicoe úmido, sem estiagem, com temperaturas do mês mais quente inferior a $22^{\circ} \mathrm{C}$.

A topografia do município é bastante acidentada, formada basicamente pelo peneplano suspenso, entre 1.700 a $2.000 \mathrm{~m}$ de altitude (Modenesi, 1984). Os pontos culminantes são o Pico do Itapeva com $2.030 \mathrm{~m}$ e o Pico do Imbiri com $1.950 \mathrm{~m}$. O relevo dominante, em que ocorrem os solos de Campos do Jordão, é montanhoso, com declives curtos e vales em " $V$ ' '; sua drenagem é moderada. O quartzo é o mineral dominante.

O solo do município é, em geral, formado de gnaisses xistosos e micaxistos, 
possuindo a profundidade de $1,50 \mathrm{~m}$ e apresentando areia argilosa e areia barrenta, sendo bastante ácido. Conforme suas bases geológicas, encontra-se um conjunto, não muito homogêneo, de solos Campos do Jordão ou Cambisolo e Latosolo vermelho-amarelo, fase rasa (Oliveira et al., 1975).

Orio mais importante do município é o Capivari, cujas nascentes se localizam nobairroUmuarama, próximo a umaUnidade de Conservação. Esteriorecebe, em seu curso, diversos tributários, entre eles os rios Perdizes e Salto, que nascem na referida área e abastecem o município.

As características turísticas da cidade levaram-na a um crescimento populacional anormal, no que se refere à sua forma, deslocando pessoas de fora, ora em caráter temporário, ora permanente, provocando um contigente acima da capacidade de uso da infra-estrutura da cidade (Paulo Filho, 1986).

A vegetação de Campos do Jordão se distribui em dois grandes tipos: a vegetação de mata e a vegetação campestre. De modo geral, se apresenta profundamente modificada pela influência do Homem. Do ponto de vista paisagístico, sobressai a presença da floresta de Araucaria-Podocarpus, dentre as formaçōes naturais, e de extensos reflorestamentos de coníferas dentre as antropogênicas (Schiavetti, 1995)

A região de Campos do Jordão se apresenta como um "locus" singular, marcado pelo encontro de três regiōes florísticas: a mata de Araucaria-Podocarpus, considerada elemento da grande região da Araucária; a Mata Latifoliada da Encosta Atlântica, participante do sistema de florestas costeiras do Brasil ou Floresta Atlântica e dos Campos do Brasil Meridional (Rizzini, 1979). Segundo Backes(1988), a região de Campos do Jordão possui a maior área de Araucárias do Estado de São Paulo.

A área do município de Campos do Jordão está legalmente protegida por diversos regimes jurídicos sobrepostos, dentre eles a declaração de APA da Mantiqueira, em nível federal, APA Estadual de Campos do Jordão e a APA Municipal, criada através da lei municipal n. 1484/85 e regulamentada pelo decreto municipaln. 1850/88.

Os Parques Estaduais de Campos do Jordão (PECJ) e dos Mananciais (PEMCJ), também com sobreposiçãoàsáreas de APAs, perfazem um total de um terço da área total do município. Além destes regimes, grande parte da área do município está regida pelo Código Florestal, em virtude da forte declividade, altitudes acima de $1.800 \mathrm{~m}$, áreas de nascentes e cursos d'água e topos de morros.

O PECJ, segundo Schiavetti et al. (1997), atraiu 1.199.083 visitantes entre o período de 1985 a 1995, gerando, após 1990, recursos para a manutenção do próprio Parque. Esta atração de visitantes fez com que diversos empreendimentos comerciais se instalassem na estrada de acesso ao mesmo, empregando diversas pessoas direta eindiretamente.

O município de Campos do Jordão possui sua maior fonte de renda na atividade turística, realizada principalmente na temporada de inverno, entre os meses de maio a julho (Barbosa, 1996). Porém, este afluxo turístico não está ligado ao setor do ecoturismo. De acordo com o trabalho de Ruschmann (1995), que levantou os locais mais visitados pelos ecoturistas brasileiros, não se inclui Campos do Jordão, fato que pode ser explicado pelos pontos discutidos em Pagani et al. (1996) sobre as necessidades do ecoturista.

A visitação intensa que ocorre no PECJ, com grande afluxo de pessoas para esta área não pode ser considerado como resultado do ecoturismo, pois segundo o trabalho de McKercher (1996) há diferenças entre o tipo de u

esse autor, o comportamento, a densidade de ocupação, o nível de experiencias e o tempo de permanência na área d

do-o como turistas ou recreacionıstas (ecoturista para o Brasil). Os visitantes do PECJ, por esta classificação, podem ser considerados turistas, haja vista a alta densidade de ocupação, o baixo nível de experiência e o pequeno tempo de permanência na área (Moraes \& Schiavetti, 1997).

Tais dados devem ser considerados para o planejamento do PEMCJ, atentando-se a sua proximidade com a área urbana do município, pois esta área está fechada ao público visitante da estância turística de Campos do Jordão, não gerando nenhum tipo de renda direta à comunidade. Seu rendimento está ligado

indireta, como produção hídrica (pois neste se encontram os rios que abastecem o município) e conservação de recursos genéticos ${ }^{3}$, bens estes de difícil quantifícação econômica(Dourojeanni,1993).

Vale citar que no plano diretor do município de Campos do Jordão prevê-se a abertura de novos atrativos turísticos na cidade, porém sem o devido planejamento de coleta de lixo, estação de tratamento de esgotos e contratação de recursos humanos capacitados. Assim a realização de um plano de atividades para o PEMCJ é de caráter urgente para sua abertura ao público visitante da cidade. Esse planejamento deve considerar a proximidade a grandes hotéis e a um dos pontos turísticos mais visitados de Campos do Jordão, o Pico do Itapeva, bem como as características do usuário real e potencial do Parque.

A visitação realizada na cidade de Campos do Jordão é de caráter sazonal, o que pode ser concluído pela análise dos dados da visitação no PECJ (Schiavetti et al., 1997). Isto é refletido nas condições dos recursos naturais e turísticos, como discutidoem Osemeobo (1989) e Magri et al. (1990). Portanto, a busca por novos locais turísticos nestas regiōes caracterizam o uso inadequado dos recursos, que devem ser substituídos por áreas não degradadas em detrimento das áreas antigas.

A procura por áreas de recreação próximas à cidade, como o PEMCJ, é conseqüência do esgotamento das áreas naturais com visitação mais antiga, ou pela degradação dos recursos, como a cachoeira Véu da Noiva, ou pelo excesso de pessoas na temporada, como no PECJ, onde encontra-se mais de 2 mil pessoas em sua zona intensiva, que possui aproximadamente 1.000 ha de área útil.

O PEMCJ não possui estrutura física e humana para o atendimento à visitação pública. Essa atividade vem acontecendo no Parque de maneira desordenada e ilegal, com a entrada de grupos a cavalo, como parte de circuitos de hipismo rural, e de

\footnotetext{
3. Potencial de uso existente na variabilidade genética, como, por exemplo, resistência a uma doença
} 
"motocross". Percebe-se assim a falta de planejamento e de recursos humanos para o gerenciamento da área, haja vista serem atividades com fortes impactos em uma área

Atualmente o turismo na área do PEMCJ pode ser considerado, segundo as relações sugeridas por Budowski (1976), como em coexistência, em que o contato é mínimo, em virtude da pequena quantidade de atividades propostas em sua área e ao desconhecimento do público em relação à existência da área.

O impacto do turismo na população de papagaios de peito roxo (Amazona vinacea), espécie de distribuição disruptiva, ameaçada de extinção e motivo da criação da área do PEMCJ, deve ser minimizado, para que não haja alteração de seu comportamento reprodutivo, como descrito por Burger \& Gochfeld (1993) e Burger et al. (1995) em aves marinhas. O pisoteio sobre áreas de nascentes e sobre as gramíneas dos campos naturais devem também ser avaliados, visando a sustentabilidade dos recursos ali conservados.

$\mathrm{Na}$ área do entorno do PEMCJ, o impacto do turismo deve ser avaliado, principalmente na estrada de acesso ao Pico do Itapeva e no limite Leste, onde a divisa é um condomínio residencial de alto padrão.

A aplicação de sistemas de informações geográficas para planejamento de Unidades deConservação pode ser considerada de extrema importância e praticidade, haja vista a facilidade na manipulação de seus dados, na quantidade/qualidade das informações geradas e na velocidade de sua obtenção.

As revisões dos planos de manejo, as quais devem ser realizadas a cada cinco anos, quando estiverem sendo ajudadas por informações georeferenciadas, serão mais rápidas e menos custosas.

Ozoneamentodos recursos naturais e turísticos, como descrito por Ruschmann (1993), é considerado um dos primeiros passos para o processo de planejamento turístico em uma localidade. Outro passo importante é a determinação dos impactos dessa atividade, utilizando-se escalas, como a proposta por Lankford \& Howard (1994).

Diversos outros estudos propõem a limitação do número de turistas e das atividades ligadas ao turismo, em especial os que tratam da capacidade suporte. Atualmente, dentre os que vêm sendo amplamente estudados e aplicados, como exemplo, pode-se citar o trabalho de Faria et al. (1995) que trata especificamente do planejamento de uma trilha interpretativa e determinação de sua capacidade de suporte.

\section{Consideraçōes Finais}

A importância atual das Unidades deConservação pode ser demonstrada pelo atual processo de criação dessas áreas em vários locais do planeta. O aumento da área total conservada, principalmente nos países de alta biodiversidade, e a crescente entrada de recursos financeiros devem ser considerados de grande importância para a efetiva implantação dessas áreas
A interação entre as atividades turísticas e o manejo das Unidades de Conservação está possibilitando a criação, implantação e alterações no manejo dessas áreas. Em locais como a Costa Rica, a África do Sul e o Quênia o ecoturismo estáentre as maiores fontes de entrada de divisas externas, e em áreas como o Parque Estadual de Campos do Jordão (SP), ou o Parque Nacional do Iguaçu (PR) a entrada de recursos financeiros jápossibilita, em grande parte, a sustentabilidade da Unidade gerando inclusive possibilidades de trabalho para a comunidade vizinha à área.

O planejamento das UC federais e estaduais brasileiras deve considerar a crescente demanda turística atual da população brasileira e internacional, criando e implantando suas Unidades de Conservação para receber o público potencial, visando, através dos recursos gerados, a maximização da conservação de sua alta biodiversidade.

O órgão administrador dos Parques Estaduais em Campos do Jordão deve realizar amplo estudo para a abertura do PEMCJ à visitação, bem como rever as áreas propícias de visitação e determinar o número máximo de visitantes para o PECJ, visando alcançar a simbiose proposta por Budowski (1976). Nestes estudos a capacidade de carga e os impactos da visitação devem ser priorizados, visando a principal função de uma Unidade de Conservação, a conservação dos recursos naturais para as futuras gerações.

\section{Referências Bibliográficas}

AULICINO, M.P. 1994. Turismo e estâncias: impactos positivos. Turismo em Anculise, São Paulo, v.5, n.2, p. 33-42, nov.

BARBOSA, C.R. 1996. O contexto do Grande Hotel no desenvolvimento turístico de Campos do Jordâo. São Paulo: Senac/Ceatel. (Trabalho de Conclusão de Curso. Pós-graduação "lato sensu" em Administração Hoteleira). 1.3p. BACKES, S. 1988. Condicionamento climálico e distribuição geográfica da Araucária angustifolia (Bert.) O. Kte no Brasil. Pesquisa Botânica, n.39, p.5-40

BLANE, J.M. \& JAAKSON, R. 1994. The impactof ecoturism boats on the St. Lawrence Beluga Whales. Environmental

BOO, E. 1990. Ecoturismo: potenciales y escollos. Washington, D.C.: WWF \& The Conservation Foundation. Vol

A.P. M. 1995. Impactos ambientais no municipio de Itapecirica da Serra - Área de protę̧ão aos mananciais - devido à expansão urbana no periodo de 1985 a 199.3. Rio Claro: UNESP. (Monografia de graduação)

Conservation, v.3, n.1, p. $27-32$ 1977. Tourism and environmental conservation: conflict, coexistence or symbiosis? Parks. v.l, n.4, p. 3-16 BURGER, J \& GOCHFELD, M. 1993. Tourism and short-term behavioural responses of nesting masked, red-footed and blue footed Boobies in the Galápagos. Environmental Conservation, v.20, n.3, p. 255-9.

BURGER, J; GOCHFELD, M. \& NILES, L.J. 1995. Ecotourism and birds in coastal New Jersey: contrasting of birds, tourists and mangers. Environmental Conservation, v.22, n. I, p. 56-65.

COLE, D.N. \& MARION, J.L. 1988. Recreation impacts in some riparian forest on the Eastern United States Environmental Management, v.12, n.l, p. 99-107.

TUNE, A. E. 1991.Turismo e meio ambiente na Amazônia - perspectivas econômicas do turismo ecológico Turismo em Análise, São Paulo, v. 2 n.1, p.53-61, maio.

CORTEZ, R.V. 1993. Una aplicación SIG en la determinación de prioridades de procteción en manejo del fuego. In SIMPÓSIO BRASILEIRO DE GEOPROCESSAMENTO 2 São Paulo. p. 651-9. 
DAVIS, F.W. et al. 1990. An information systems approach to the preservation of biological diversity. Int. J Geographical Information S!:stem.s, v.4, n.l, p. 55-78

DOUROJEANNI, M. 1993. Evaluación ecológica y económica de las áreas protegidas. In: BARZETTI, V. (Ed Parques y progressso: areas protegidas y desarrollo econômico en América Latina y el Caribe. Washington
UICN. p. 143-71.

DURBIN, J.C. \& RALAMBO, J.A. 1994. The role of local people in the sucessful maintenence of protected areas in Madagascar. Environmental Conservation,v.21, n.2, p. 115-20.

DUFFUS, D.A. \& DEARDEN, P. 1993. Recreacional use, valuation, and management, of Killer Whales (Orcinus orca) on Canada's Pacific Coast. Environmental Conservation, v.20, n.2, p.149-156.

EMPRESA BRASILEIRA DE TURISMO. 1991. Programa ecoturismo. Brasília: EMBRATUR. 56p. (Versāo Preliminar).

FARIA, H. H. et al. 1995. Planejamento de uma trilha interpretativa e determinação da sua capacidade de carga. In ANAIS CONGRESSO BRASILEIRO DE DEFESA DOMEIO AMBIENTE, 4. Riode Janeiro: UFR J. p. 259-274 FERRĀO et aI. 1992. Guia Brasil de turismo ecolígico. Rio de Janeiro: Libres. $189 \mathrm{p}$.

FURLAN, S. 1996. Unidades de conservação insular: consideraçōes sobre a dinâmica insular, planos de manejo turismo ambiental. In: DE LEMOS, A.I. (Org.) Turismo: impactoss socioambientais. São Paulo: Hucitec.

HAWKINS, J.P. \& ROBERTS, C. M. 1994. The growth of coastal tourism in the red sea: present and future effects on coral reefs. Ambio, v. 23, n.8, p. $503-508$

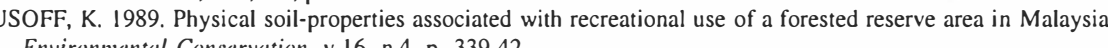
Environmental Conservation, v. 16, n.4, p. 339-42.

AANFORD, S.V. \& HOWARD, D.R. 1994. Developing a tourism impact attidude scale. Annals of Tourism

LIDDLE, M.J. \& KAY, A.M. 1987. Resistance, survival and recovery of trampled corals on the Great Barrier Reef Biological Conservation, v.42, n.I, p. I-18.

MENDES, F.B.G. 1990. Características do usuário do Parque Estadual da ltha Anchieta - subsídios para o plano interpretativo. In: CONGRESSO FLORESTAL BRASILEIRO, 6. Anais... p.

MARIANI, M. A. P. \& GONÇALVES, H.C. 1996. Os impactos ambientais decorrentes das atividades turisticas no Pantanal Sul-Matogrossense (MS, Brasil). In: DE LEMOS, A.I. (Org.). Turismo: impactossocioumbientuis. São Paulo: Hucitec. McKERCHER, B.

p. 563-75. Rev. $I G$, v. 5, n. $1 / 2$, p. $7-13$.

MORRIS, A. \& DICKINSON, G. 1987. Tourism development in Spain: growth versus conservation on the Costa Brava. Geography, v.72, n.3/4, p. 16-25.

MORAES, M.E.B. \& SCHIAVETTI, A. 1997. Caracterização do perfis dos moradores e visitantes do Parque Estadua de Campos do Jordăo: subsidios para a coleta seletiva de lixo. In: SIMPÓSIO CIÊNCIAS DA ENGENHARIA AMBIENTAL, 4. São Carlos: CRHEA, USP. Anais..., p. 167-9.

NELSON, J.G. 1994. The spread of ecotourism; some planning implications. Environmental Conservation, v.21, n..3 p. $248-55$.

OLIVEIRA, J.B.; MENK, J.R.F. \& ROTTA, C.L. 1975. Solos do Parque Estadual de Campos do Jordão. Silviculturu em Säo Paulo, n. 9, p. 125-56.

ORTEGA, R.D; WHINTER, J.R.C. \& RIBEIRO, W. 1992. Planejamento ambiental e desenvolvimento do ecoturismo Turismo em Análise, São Paulo, v.3 n.1, p. 51 1-9, maio.

OSEMEOBO, G.J. 1989. Forest recreational land-use and zoological gardens in a developing economy: the case of Southern Nigeria. Environmental Conservation, v.16, n.1, p. 69-74.

ÁDUA, S.M. 1994. Conservation awareness through an environmental education programme in a Atlantic Forest of Brasil. Environmental Conservation, v.21, n.2, p. 145-51.

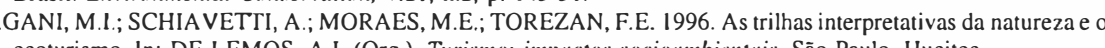
ecoturismo. In: DE LEMOS, A.l. (Org.). Turismo: impactos socioambientais. São Paulo. Hucitec.

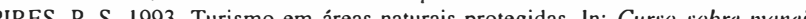
Curiba. Universidde Live do Meio Ambiente.

Brusil. São Paulo: Hucitec, EDUSP. 62 p.

RUSCHMANN, D. V. M. 1992. Turismo sustentado para apreservação do patrimônio ambiental. Turismo em Análise. São Paulo, v. 3 n.I, p. 42-50, maio

993. Impactos ambientais do turismo ecológico no Brasil. Turismo em Análise, São Paulo, v.4 n.I, p. 56-68,
1995. Turismo ecológico no Brasil - Dificuldades para sua caracterização. Turismo em Análise, São Paulo, v.6 n.1. p. 16-24, maio.

SCHIAVETTI A 1995. Campos do Jordāo State Park. In: HENRY, R. \& SENNA, P. A.C. XXVISIL CONGRESS. São Paulo: Mid-Congress Excursions. p. 35-6.

1997. Proposta de zoneamento recreativo para o Parque Estadual dos Mananciais de Campos do Jordāo. _ubsílios para o plano de manejo. São Carlos:USP. 81p.(Dissertaçāo em Ciências Engenharia Ambiental). SCHIAVETTI, A.; ROBIM, M.J. \& MORAES, M.E.B. 1997. Parque Estadual de Campos do Jordāo: análise quantitativa da visitação pública. Turismo em Análise. São Paulo, v.8 n.2, p. 13-20, nov.

SETZER, J. 1966. Atlas. climatológico e ecolígico do Estado de Sũo Paulo. Comissão Interestadual da Bacia ParanáUruguai. São Paulo: CESP. 54 p

SCOTT, J.M. et al. 1987. Species richness: a geographic approach to protecting future biological diversity. Bioscience,

v.37, n.11, p. 782-88.
SERSON, J. 1992. Ecoturismo e desenvolvimento sustentado. Turismo em Análise. São Paulo, v.3 n. 1, p. 37-41, maio SINHA, A.R.P. 1992. Impacts of growing population and tourism on the endemic flora of $\Lambda$ daman and Nicobar Island Environmental Conservation, v.19, n.2, p. 173-4, 183

STANKEY, G.H. 1989. Tourism and National Parks: peril and potencial. In: BATENSON, P.; NYMAN, S. \& TOMMASI L R. 1992 Recifes artificiaise sunimporância para o tursmo nas regīes costeins Turismo em Anilive ULIK O 1992 Turismo e meio amben

- identificação e possibilidades da oferta alternativa. Turismo em Anúlise. São Paulo, v.3 n.1, p. 21-30, maio.

\section{Recebido em $23 / 11 / 98$}

Aprovado em 15/12/98 maio. 